\title{
The practice of e-commerce and its obstacles: A field study on SMEs in the Al-Qassim region
}

\author{
Haitham Nakhleh* \\ College of Business and Economics, Qassim University, Buraydah, Saudi Arabia
}

\section{A RT ICLE INFO}

\section{Article history:}

Received 9 January 2017

Received in revised form

17 April 2017

Accepted 18 May 2017

\section{Keywords:}

E-commerce

Organizational factors

Technological factors

Environmental factors

\begin{abstract}
A B S T R A C T
The aim of this study was to explore the practice of e-commerce among SMEs in Al-Qassim region, Saudi Arabia and the obstacles to e-commerce faced by managers. In order to collect the required data, a questionnaire was developed on the basis of an extensive review of the literature, and this was distributed to a sample of 100 SMEs in the Al-Qassim region. Of the distributed questionnaires, 74 completed questionnaires were returned, giving a response rate of $74 \%$. The questionnaire comprised four main domains: the practice of e-commerce as a dependent variable while organizational, technological and environmental factors as independent variables. Each of the independent domains covered six dimensions. The results of the study supported the hypotheses that organizational factors (top management support, employee skills and experience, and business strategy alignment), technological factors (internet service quality, information technology security, perceived benefits, e-payment services, and number of technical officers), and environmental factors (customer preferences, industry characteristics, socio-cultural factors, and competitor pressure) have significant and positive relationships with the practice of ecommerce in SMEs. The absence of these factors can therefore be regarded as a barrier to the practice of e-commerce.
\end{abstract}

(C) 2017 The Authors. Published by IASE. This is an open access article under the CC BY-NC-ND license (http://creativecommons.org/licenses/by-nc-nd/4.0/).

\section{Introduction}

Small and medium-sized enterprises (SMEs) form about $90 \%$ of business enterprises in Saudi Arabia. SMEs in Saudi Arabia include companies in the micro, small, and medium categories. These enterprises can be defined in terms of the number of their employees. Micro enterprises have one or two employees, small enterprises between three and 49 employees, and medium enterprises between 50 and 200 employees (JEG, 2016). Ezzi (2015) indicated that the practice of e-commerce by Saudi SMEs has been enhanced because of several developments initiated in Saudi Arabia. Examples of these developments include the electronic payment system introduced by the Saudi Arabian Monetary Authority, which is an online system dedicated to bill payments and fund transfers, and developments introduced by Saudi Post such as electronic delivery methods and an e-shopping portal. The author reported that e-commerce sales amounted to about

\footnotetext{
* Corresponding Author.

Email Address: hm.hakhleh@qu.edu.sa

https://doi.org/10.21833/ijaas.2017.06.023

2313-626X/C 2017 The Authors. Published by IASE.

This is an open access article under the CC BY-NC-ND license

(http://creativecommons.org/licenses/by-nc-nd/4.0/)
}

$10 \%$ of the total retail sales in 2015. As for the growth rate of e-commerce among large companies, Albugami and Ahmed (2015) mentioned that in 2014 Saudi Arabia had the highest rate of growth among Middle East and North African countries.

However, the practice of e-commerce among SMEs is still in its initial stages. Ezzi (2015) stated that in 2009 only $12 \%$ of Saudi SMEs had a dynamic website and that about $88 \%$ of such enterprises had no e-payment services. The percentage of companies using dynamic websites had grown to 33\% by 2015 . With respect to barriers to e-commerce business in Saudi Arabia, Ezzi (2015) declared that risk is the key barrier to the use of e-commerce by customers; this risk is the risk to customer privacy, the risk of a lack of commitment by the vendor, and financial risk. Another barrier to the use of e-commerce by customers is their preference for actual shopping rather than virtual shopping. They regard the internet as a source for searching for products but not for buying them. For the enterprises, it was concluded that a lack of management support, a management that was unsure of the perceived benefits, a resistance to change, and the high cost of starting up e-commerce services were barriers to the use of e-commerce. 
In order to study e-commerce practice in SMEs in Saudi Arabia, an intensive literature review was carried out of studies from Saudi Arabia and other countries. The findings of the review were that numerous factors affect the practice of e-commerce. These factors were categorized into three main types: organizational, technological and environmental factors (Bahaddad et al., 2012; Ajmal and Yasin, 2012; Shemi and Procter, 2013). The primary aim of this study is to study the practice of e-commerce in SMEs in Saudi Arabia, and the obstacles met by these enterprises.

\section{Literature review, research hypotheses and model}

\subsection{Factors enhancing and inhibiting the practice of e-commerce}

Senarathna and Wickramasuriya (2001) proposed that the adoption of e-commerce in SMEs in Sri Lanka is a function of numerous variables such as top management support, organizational culture, and the availability of technological resources (measured by such things as the number of personal computers, website presence, and the number of technical officers), internet access methods, and the presence of backup facilities. Their results indicated that top management support, website presence and organizational culture, particularly an adhocracy culture, have significant effects on the adoption of ecommerce.

MacGregor and Vrazalic (2004) studied the adoption of e-commerce in SMEs in Australia and Sweden, and indicated that the most significant obstacles to the adoption of e-commerce are a lack of fitness between e-commerce and business ways, a lack of technical knowledge, security risks, and the high cost of implementation. One of the most vital factors cited by Kartiwi (2006) that help the adoption of e-commerce in SMEs in Indonesia is the alignment of business strategy with the adoption of e-commerce.

Wilson et al. (2008) studied the diffusion of ecommerce in the United Kingdom. Their results revealed five factors that affect the adoption of ecommerce: top management support, availability of information technology (IT) skills, availability of consultants, perceived benefits of e-commerce and ecommerce priority. Lip-Sam and Hock-Eam (2011) explored the factors that affect the adoption of ecommerce among SMEs in Malaysia, using a framework consisting of three factors: organizational, technological and external factors. According to them, the influential organizational factors are organizational readiness, technological factors including IT strategy and security as well as internet service quality, and external factors relate to external support from government and expertise.

The case of e-commerce adoption in South Africa was studied by Chiliya et al. (2011). The study provides insights on the following barriers: absence of government support and employee training, employee resistance, low levels of IT investment, lack of perceived benefits, and lack of security. Nezakati et al. (2012) assessed the adoption of ecommerce in Malaysia, Singapore and Thailand, and found that technical knowledge in e-commerce, perceived usefulness of e-commerce applications, and perceived benefits of e-commerce were the most important challenges to the adoption and use of ecommerce. Using a sample of 227 participants from Saudi Arabia, El-Sofany et al. (2012) investigated the influence of trust factors on the development and improvement of e-commerce. According to these authors, relevant trust factors include five groups of sub-factors - e-commerce-related factors (e.g. secured financial services), marketing factors (e.g. approaching the right target), security factors (e.g. privacy and e-payment availability), human interaction factors (e.g. understanding of users' expectations), and knowledge factors (e.g. website richness).

Zaied (2012) examined the barriers to the adoption of e-commerce among SMEs in Egypt, looking at several factors among organizational, political, legal, economical, technical, social and cultural factors. The results show that the most important barriers to the adoption of e-commerce include high costs, employees' resistance to change, the absence of technical officers, a lack of ecommerce standards and a legal framework, low levels of internet security, continuous modifications in government policies and regulations, a lack of awareness of e-commerce benefits, and restricted use of e-payment services. Bahaddad et al. (2012) explored the practice of e-commerce among Saudi plants using the following factors: organizational and human factors, technological and environmental factors, and traditional and cultural factors, collecting data from a sample of 110 SMEs in Saudi Arabia. Their results revealed that experience and skills in IT, IT education, website characteristics, communications, and security of payment methods were the most critical factors affecting the practice of e-commerce. Ajmal and Yasin (2012) proposed a model for the adoption of e-commerce in SMEs that consisted of two types of variables: external and internal variables. External variables included environmental variables such as competitive pressure and government support. On the other hand, internal variables encompassed organizational, managerial, technological, individual (education and skills), trust (security and privacy), and implementation issues (e.g. products, payment and delivery). Blackburn and Athayde (2000) point out that the level of international marketing in the addition to the size and industry of the business are business characteristics that are closely related to adoption of E-commerce.

Abdulkader and Abualkishik (2013) identified the following barriers to e-commerce adoption: high costs of implementation, lack of hardware, software requirements, and lack of technical staff, low levels of internet security, change management issues and the new behaviour needed to conduct this business. 
Ochola (2013) used a sample of 540 micro, small and medium enterprises from Kenya in order to study the determinants of e-commerce adoption among SMEs. The research model of that study covers three main factors: organizational factors (e.g. company and manager profiles), technological factors (e.g. compatibility and confidentiality) and environmental factors (e.g. customer, supplier, and competitor pressures).

Shemi and Procter (2013) categorized the obstacles to the practice of e-commerce into the following groups: organizational factors (e.g. skilled staff, finance, and culture), technological factors (e.g. internet access and speed), environmental factors (e.g. regulations, nature of the industry and local business environment) and management factors (e.g. management vision, perceived benefits, and management characteristics).

Poorangi et al. (2013) used Rogers' model (Diffusion and Innovation) to investigate the factors affecting the adoption of e-commerce in SMEs in Malaysia. The conceptual framework of their study was developed based on seven factors: relative advantage of innovation, observability, compatibility, trialability, complexity, management confidence, and employee resistance to change.

On the other hand, Mohammed et al. (2013) summarized the barriers to e-commerce adoption in SMEs as the following: the size of the enterprise, the lack of technical staff, the opinion of the management or owner, a wish to avoid risk and complex applications, financial constraints, a low level of market share, the lack of IT infrastructure, there being no perceived benefits, and a lack of government support. For Mutua et al. (2013), the cost of e-commerce applications, a lack of ecommerce experience and skills, along with internet security, were the major obstacles to e-commerce practice in SMEs.

Bagale (2014) studied the influence of organizational factors on the implementation of ecommerce in SMEs in India, and found that both organizational and technological factors had a significant impact on e-commerce adoption and use.

Almaimouni et al. (2014) explored social influence (the perception of others' beliefs about adopting or using a new system) on e-commerce use in Saudi Arabia, using a sample of 90 micro and small enterprises. Their results clarified that the intention to use e-commerce is significantly affected by personal social influence, business social influence, perceived ease of e-commerce use, and perceived usefulness of e-commerce.

Rumanyika and Mashenene (2014) found that there were the following obstacles to e-commerce practice: poor technological infrastructure, absence of IT education, training and expertise, a low level of organizational readiness, and dissenting sociocultural beliefs.

Zafar et al. (2015) confirmed the importance of information systems for SMEs in Saudi Arabia. They argued that these SMEs are still experiencing poor information technology and a lack of the necessary related skills. In their study on e-commerce in China, Chen and Zhang (2015) studied three types of factors that influence the use of e-commerce: an organizational factor (organization size), a technological factor (IT investment), and two environmental factors (market structure and network facilities). In a study carried out on Tunisian micro-enterprises, Omri et al. (2015) found that human, social, and financial factors have a significant relationship with small business success, and that the relationship is mediated by innovation.

Fahruzzaman and Subriadi (2015) analysed the adoption of e-commerce by SMEs from Indonesia, and highlighted numerous factors that affect this, such as company size, employee training, government support, user awareness of e-commerce use, IT infrastructure, compatibility of the enterprise with e-commerce, and management opinion.

In their study on SMEs in Kuwait, Al-Alawi and AlAli (2015) concluded that there were significant relationships between e-commerce adoption and top management support, the perceived benefits of ecommerce, and government regulations.

In their study on SMEs in Nigeria, Agwu and Murray (2015) considered barriers to the adoption of e-commerce. Their study demonstrated that the following barriers exist: first, factors related to the external environment, such as socio-cultural factors and external pressures; second, factors related to the internal environment, such as size, resources and culture; and finally, the perception of risks, benefits, cost and trust.

Rahayu and Day (2015) found that the usage of ecommerce in Indonesia depends on factors such as the readiness of the enterprise for technology, its IT competences and skills, innovation, management characteristics, and the perceived benefits of the utilization of e-commerce. According to Kit et al. (2015), organizational factors such as organizational size and technological factors have a significant impact on e-commerce, while environmental factors such as external pressures from competitors and suppliers have no significant impact on e-commerce adoption.

Okadapau and Emaase (2016) investigated the influence of five socio-cultural factors such as decision making process, trading partner relationships with the company, maintenance of a good company image, Personal innovation and creativity and socializing on e-Commerce. However, it is observed that the most important socio-cultural factors rated by respondents in applying ecommerce applications were: relationship of trading partners and suppliers with the company, develop business contacts by socializing, and finally maintain the image of the company.

Chivasa and Hurasha (2016) found a significant relationship between e-commerce usage and other factors such as internet cost, top management support, financial risks, management familiarity with the benefits of e-commerce, and IT infrastructure. In a study on the e-commerce challenges faced by SMEs in Nigeria, Akanbi (2016) found that IT 
infrastructure, customers' resistance to change, finance, and organizational structure were key challenges for e-commerce success.

Rehman and Alam (2016) divided e-commerce barriers into organizational (the perceived benefits of e-commerce), financial (the cost of investment in technology), technical (the cost of software), legal (ecommerce laws) and behavioural barriers (resistance to change). According to the JEG (2016) on SMEs, the lack of IT infrastructure is one of the most important challenges faced by SMEs in Saudi Arabia. After considering various literatures, it was preferred to sum up the factors that may affect the practice of e-commerce in one table to facilitate referring to them.

Thus, Table 1 shows the organizational, technological, and environmental factors that may affect the practice of e-commerce.

Table 1: Factors affecting the practice of e-commerce in SMEs

\begin{tabular}{|c|c|}
\hline Factors affecting practice of e-commerce & References \\
\hline Organizational factors & Senarathna and Wickramasuriya (2001) \\
\hline Strategic objectives & MacGregor and Vrazalic (2004) \\
\hline Organizational readiness & Kartiwi (2006) \\
\hline Top management opinion & Wilson et al. (2008) \\
\hline $\begin{array}{l}\text { lop management support } \\
\text { Training and skills development }\end{array}$ & Lip-Sam and Hock-Eam (2011) \\
\hline Employee experience & Chiliya et al. (2011) \\
\hline Organizational resistance to change & AlGhamdi et al. (2012) \\
\hline Communication processes & Shemi (2012) \\
\hline $\begin{array}{l}\text { Size of organization } \\
\text { Financial resources }\end{array}$ & El-Sofany et al. (2012) \\
\hline $\begin{array}{l}\text { Financial resources } \\
\text { Personal and business social influence }\end{array}$ & Nezakati et al. (2012) \\
\hline Business strategy alignment & Zaied (2012) \\
\hline Project management & Ajmal and Yasin (2012) \\
\hline Technological factors & Bahaddad et al. (2012) \\
\hline Information technology strategy & Danduladu et di. (2012) \\
\hline Information technology security & Ochola (2013) \\
\hline Internet service quality & Poorangi et al. (2013) \\
\hline Presence of a dynamic website & Shemi and Procter (2013) \\
\hline Number of technical officers & Abdulkader and Abualkishik (2013) \\
\hline $\begin{array}{l}\text { Internet cost } \\
\text { Isers' }\end{array}$ & Mohammed et al. (2013) \\
\hline $\begin{array}{l}\text { Users' ability to use e-commerce } \\
\text { Information technology infrastructure }\end{array}$ & Mutua et al. (2013) \\
\hline Employee IT knowledge & Almaimouni et al. (2014) \\
\hline Security risks & Bagale (2014) \\
\hline Network size & Rumanyika and Mashenene (2014) \\
\hline Perceived benefits of e-commerce & Ezzi (2015) \\
\hline $\begin{array}{l}\text { Perceived ease of e-commerce applications } \\
\text { Cost of e-commerce applications }\end{array}$ & Kit et al. (2015) \\
\hline E-payment services & Omri et al. (2015) \\
\hline Environmental factors & Al-Alawi and Al-Ali (2015) \\
\hline Industry characteristics & Agwu and Murray (2015) \\
\hline Market structure and share & Chen and Zhang (2015) \\
\hline $\begin{array}{l}\text { Government regulations and support } \\
\text { Expertise support }\end{array}$ & Fahruzzaman and Subriadi (2015) \\
\hline E-commerce business standards and laws & Rahayu and Day (2015) \\
\hline Competitors' and suppliers' pressure & Chivasa and Hurasha (2016) \\
\hline Customers' needs and preferences & Rehman and Alam (2016) \\
\hline $\begin{array}{l}\text { Customers' fear of related risks } \\
\text { Economic recession }\end{array}$ & Zhu and Kraemer (2005) \\
\hline Socio-cultural factors & Zhu and Kraemer (2002) \\
\hline
\end{tabular}

\subsection{Research hypotheses}

Based on the above literature review, the following hypotheses were suggested. Hypotheses 1.1-1.6 refer to organizational factors, hypotheses 2.1-2.6 concern technological factors, and finally, hypotheses 3.1-3.6 relate to environmental factors.

H1: there is a significant relationship between organizational factors (1.1 top management support, 1.2 resistance to change, 1.3 employee experience, 1.4 business strategy alignment, 1.5 financial resources and, 1.6 communication processes) and the practice of e-commerce in SMEs.

H2: there is a significant relationship between technological factors (2.1 internet service quality, 2.2 information technology security, 2.3 number of technical officers, 2.4 perceived benefits, and, 2.5 cost of hardware and software, and, 2.6 e-payment services) and the practice of e-commerce in SMEs.

H3: there is a significant relationship between environmental factors (3.1 government regulations, 3.2 e-commerce standards, 3.3 competitors' pressure, 3.4 industry characteristics, 3.5 customers' preferences, and, 3.6 socio-cultural factors) and the practice of e-commerce in SMEs.

\subsection{Research model}

Fig. 1 displays the conceptual framework for the study. As can be seen, the model consists of three main independent variables (organizational, technological and environmental factors) and one dependent variable (e-commerce practice). 


\section{Research methodology}

\subsection{Research sample and data collection}

The sample of this study consisted of 100 SMEs in the Al-Qassim region of Saudi Arabia. The questionnaire that had been developed to collect the required data was distributed to 100 participants. The total number of questionnaires returned was 74 , giving a response rate of $74 \%$.

\subsection{Measures}

The conceptual model of the current study contains one dependent variable (e-commerce) and it was measured based on previous studies (Senarathna and Wickramasuriya, 2001; MacGregor and Vrazalic, 2004; Kartiwi, 2006), ten items were developed to measure this variable, and three independent variables: organizational, technological and environmental factors.

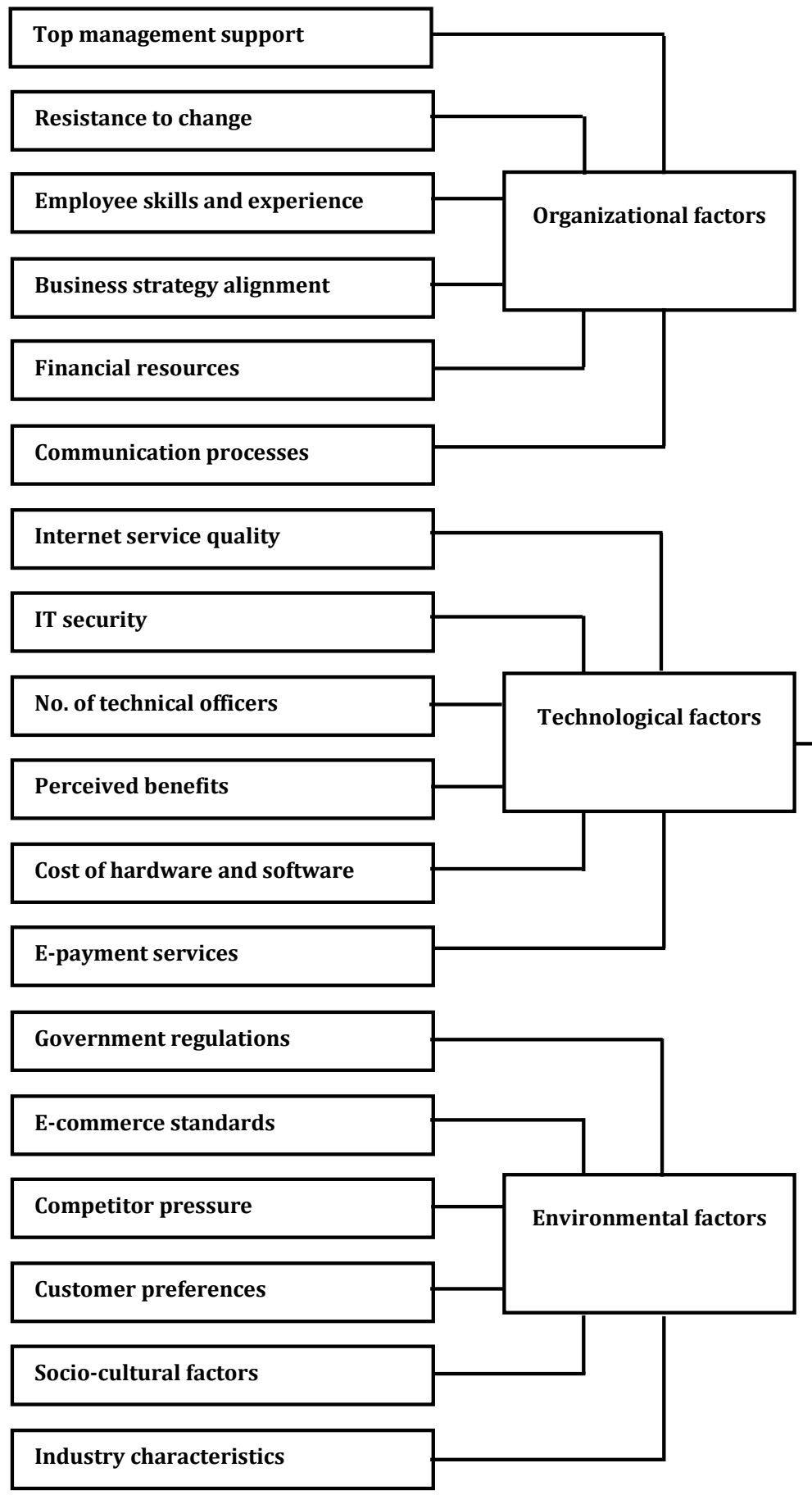

Fig. 1: Research model

Each of these factors was measured using six subfactors extracted from the literature, as shown in Table 2.

The sub-factors were measured using two items for each. Therefore, the total number of items in the questionnaire was 46. The questionnaire was anchored with a scale consisting of five points $(1=$ strongly disagree, 2 = disagree, 3 = unsure, 4 = agree, and 5 = strongly agree). 


\subsection{Validity and reliability}

Table 3 shows the values of the average variance extracted (AVE) and the values of Cronbach's alpha, with which validity and reliability were assessed. As can be noted, all AVEs were greater than 0.5 and the reliability coefficients were greater than 0.60 , meaning that the survey employed in this study is valid and reliable.

\section{Results}

\subsection{Correlation analysis}

From the results for the correlation between the organizational factors and the practice of ecommerce, as shown in Table 4, there is a statistical correlation between all the independent factors and the practice of e-commerce. Top management support has the greatest correlation with the practice of e-commerce $(r=0.493)$, followed by employee skills and experience $(r=0.483)$, business strategy alignment $(r=0.468)$, financial resources $(r$ $=0.399)$, and resistance to change $(r=0.324)$. The lowest correlation value was found between communication processes and the practice of ecommerce $(r=0.1)$.

For technological factors, the results shown in Table 5 indicate that all dimensions of technological factors have significant relationships with the practice of e-commerce. The largest correlation was with internet service quality $(r=0.551)$, followed by the perceived benefits ( $\mathrm{r}=0.423$ ), IT security ( $\mathrm{r}=$ $0.399)$, e-payment services $(r=0.386)$, number of technical officers $(r=0.367)$ and finally the cost of hardware and software $(r=0.362)$.

Table 2: Measures of organizational, technological, and environmental factors

\begin{tabular}{cll}
\hline Factors & \multicolumn{1}{c}{ Sub-factors } & \multicolumn{1}{c}{ Authors } \\
\hline & Top management support & Bagale (2014) \\
& Resistance to change & Almaimouni et al. (2014) \\
Organizational factors & Employee skills and experience & Rumanyika and Mashenene (2014) \\
& Business strategy alignment & Omri et al. (2015) \\
& Financial resources & Agwu and Murray (2015) \\
& Communication processes & Al-Alawi and Al-Ali (2015) \\
& Internet service quality & Ezzi (2015) \\
& IT security & Chen and Zhang (2015) \\
& No. of technical officers & Fahruzzaman and Subriadi (2015) \\
& Perceived benefits & Zafar et al. (2015) \\
& Cost of hardware and software & Rahayu and Day (2015) \\
& E-payment services & Kit et al. (2015) \\
& Government regulations & Rehman and Alam (2016) \\
& E-commerce standards & Akanbi (2016) \\
& Competitor pressure & Chivasa and Hurasha (2016) \\
& Customer preferences & Zhu and Kraemer (2005) \\
& Industry characteristics & Zhu and Kraemer (2002) \\
\hline
\end{tabular}

Table 3: Validity and reliability results

\begin{tabular}{|c|c|c|c|}
\hline Variables & No. of items & Cronbach's Alpha & AVE \\
\hline 1. Organizational factors & 12 & 0.83 & 0.77 \\
\hline 1.1 Top management support & 2 & & \\
\hline 1.2 Resistance to change & 2 & & \\
\hline 1.3 Employee skills and experience & 2 & & \\
\hline 1.4 Business strategy alignment & 2 & & \\
\hline 1.5 Financial resources & 2 & & \\
\hline 1.6 Communication processes & 2 & & \\
\hline 2. Technological factors & 12 & 0.87 & 0.71 \\
\hline 2.1 Internet service quality & 2 & & \\
\hline 2.2 IT security & 2 & & \\
\hline 2.3 No. of technical officers & 2 & & \\
\hline 2.4 Perceived benefits & 2 & & \\
\hline 2.5 Cost of hardware and software & 2 & & \\
\hline 2.6 E-payment services & 2 & & \\
\hline 3. Environmental factors & 12 & 0.79 & 0.69 \\
\hline 3.1 Government regulations & 2 & & \\
\hline 3.2 E-commerce standards & 2 & & \\
\hline 3.3 Competitor pressure & 2 & & \\
\hline 3.4 Industry characteristics & 2 & & \\
\hline 3.5 Customer preferences & 2 & & \\
\hline 3.6 Socio-cultural factors & 2 & & \\
\hline
\end{tabular}

In relation to environmental factors, the results highlighted in Table 6 showed that industry characteristics have the greatest correlation with the practice of e-commerce ( $\mathrm{r}=0.537)$.

Additionally, the results showed that customer preferences were the second major factor associated with e-commerce $(r=0.498)$, followed by sociocultural factors $(\mathrm{r}=0.469)$, competitor pressure $(\mathrm{r}=$ $0.366)$, then government regulations $(r=0.322)$. It was revealed that e-commerce standards was the factor that has the lowest correlation with ecommerce $(r=0.210)$. 


\subsection{Regression analysis}

Simultaneous regression analysis was conducted in order to identify the influence of each independent variable on the practice of e-commerce. The results, shown in Table 7, were that 12 out of the 18 sub-hypotheses were accepted.

Table 4: Results of correlation analysis between organizational factors and e-commerce

\begin{tabular}{|c|c|c|c|c|c|c|c|}
\hline & 1 & 2 & 3 & 4 & 5 & 6 & 7 \\
\hline 1 & - & 0.401 & 0.397 & 0.511 & 0.278 & 0.229 & 0.493 \\
\hline 2 & & - & 0.361 & 0.119 & 0.147 & 0.301 & 0.324 \\
\hline 3 & & & - & 0.331 & 0.450 & 0.312 & 0.483 \\
\hline 4 & & & & - & 0.284 & 0.350 & 0.468 \\
\hline 5 & & & & & - & 0.109 & 0.399 \\
\hline 6 & & & & & & - & 0.104 \\
\hline 7 & & & & & & & - \\
\hline
\end{tabular}

Table 5: Results of correlation analysis between technological factors and e-commerce

\begin{tabular}{|c|c|c|c|c|c|c|c|}
\hline & 1 & 2 & 3 & 4 & 5 & 6 & 7 \\
\hline 1 & - & 0.330 & 0.211 & 0.440 & 0.364 & 0.245 & 0.551 \\
\hline 2 & & - & 0.300 & 0.411 & 0.240 & 0.301 & 0.399 \\
\hline 3 & & & - & 0.101 & 0.315 & 0.298 & 0.367 \\
\hline 4 & & & & - & 0.472 & 0.366 & 0.423 \\
\hline 5 & & & & & - & 0.313 & 0.262 \\
\hline 6 & & & & & & - & 0.386 \\
\hline 7 & & & & & & & - \\
\hline
\end{tabular}

Table 6: Results of correlation analysis between environmental factors and e-commerce

\begin{tabular}{|c|c|c|c|c|c|c|c|}
\hline & 1 & 2 & 3 & 4 & 5 & 6 & 7 \\
\hline 1 & - & 0.339 & 0.177 & 0.219 & 0.360 & 0.108 & 0.322 \\
\hline 2 & & - & 0.250 & 0.241 & 0.258 & 0.118 & 0.210 \\
\hline 3 & & & - & 0.389 & 0.420 & 0.255 & 0.366 \\
\hline 4 & & & & - & 0.385 & 0.312 & 0.537 \\
\hline 5 & & & & & - & 0.400 & 0.498 \\
\hline 6 & & & & & & - & 0.469 \\
\hline 7 & & & & & & & - \\
\hline
\end{tabular}

The practice of e-commerce is affected by top management support $(\beta=0.447)$, employee skills and experience $(\beta=0.436)$, perceived benefits $(\beta=$ $0.421)$, socio-cultural factors $(\beta=0.411)$, industry characteristics $(\beta=0.396)$, IT security $(\beta=0.368)$, business strategy alignment $(\beta=0.353)$, customer preferences $(\beta=0.0 .348)$, competitor pressure $(\beta=$ $0.336)$, e-payment services $(\beta=0.321)$, and the number of technical officers $(\beta=0.294)$.

\section{Discussion}

This study explores the practice of e-commerce among SMEs in Al Qassim region, Saudi Arabia and the obstacles to this practice from the managers' point of view. The results indicated that organizational factors such as top management support, employee skills and experience, and business strategy alignment have significant influences on the practice of e-commerce in SMEs.

These results are in agreement with the works of Senarathna and Wickramasuriya (2001), Tsao et al. (2004), Kartiwi (2006), Wilson et al. (2008), Chiliya et al. (2011), El-Sofany et al. (2012), Bahaddad et al. (2012), Ajmal and Yasin (2012), Shemi and Procter (2013), Mutua et al. (2013), Rumanyika and Mashenene (2014), Fahruzzaman and Subriadi (2015), Al-Alawi and Al-Ali (2015) and Chivasa and Hurasha (2016).
However, the other organizational factors (resistance to change, financial resources, and communication processes) have no significant influence on the practice of e-commerce in SMEs. This paper confirmed the significant relationships between the practice of e-commerce and top management support, employee skills and experience, and business strategy alignment.

The results also showed that technological factors such as perceived benefits, IT security, e-payment services, and the number of technical officers have significant effect on the practice of e-commerce by SMEs. The same results were revealed by Wilson et al. (2008), Nezakati et al. (2012), Cosgun and Dogerlioglu (2012), Shemi and Procter (2013), Mohammed et al. (2013), Almaimouni et al. (2014), Al-Alawi and Al-Ali (2015), Agwu and Murray (2015), Rahayu and Day (2015), Chivasa and Hurasha (2016), and Rehman and Alam (2016). The only factor that has no influence on the practice of ecommerce is the Cost of hardware and software. Finally, the results indicated that environmental factors such as socio-cultural factors, industry characteristics, customer preferences, and competitor pressure have influence on the practice of e-commerce.

In the works of Blackburn and Athayde (2000), MacGregor and Vrazalic (2004), El-Sofany et al. (2012), Zaied (2012), Ajmal and Yasin (2012), 
Ochola (2013), Shemi and Procter (2013), Mutua et al. (2013), Bagale (2014), Almaimouni et al. (2014), Rumanyika and Mashenene (2014), Ezzi (2015), Chen and Zhang (2015) and Al-Alawi and Al-Ali
(2015) the same factors were found to have a significant relationship with the practice of ecommerce.

Table 7: Results of simultaneous regression analysis

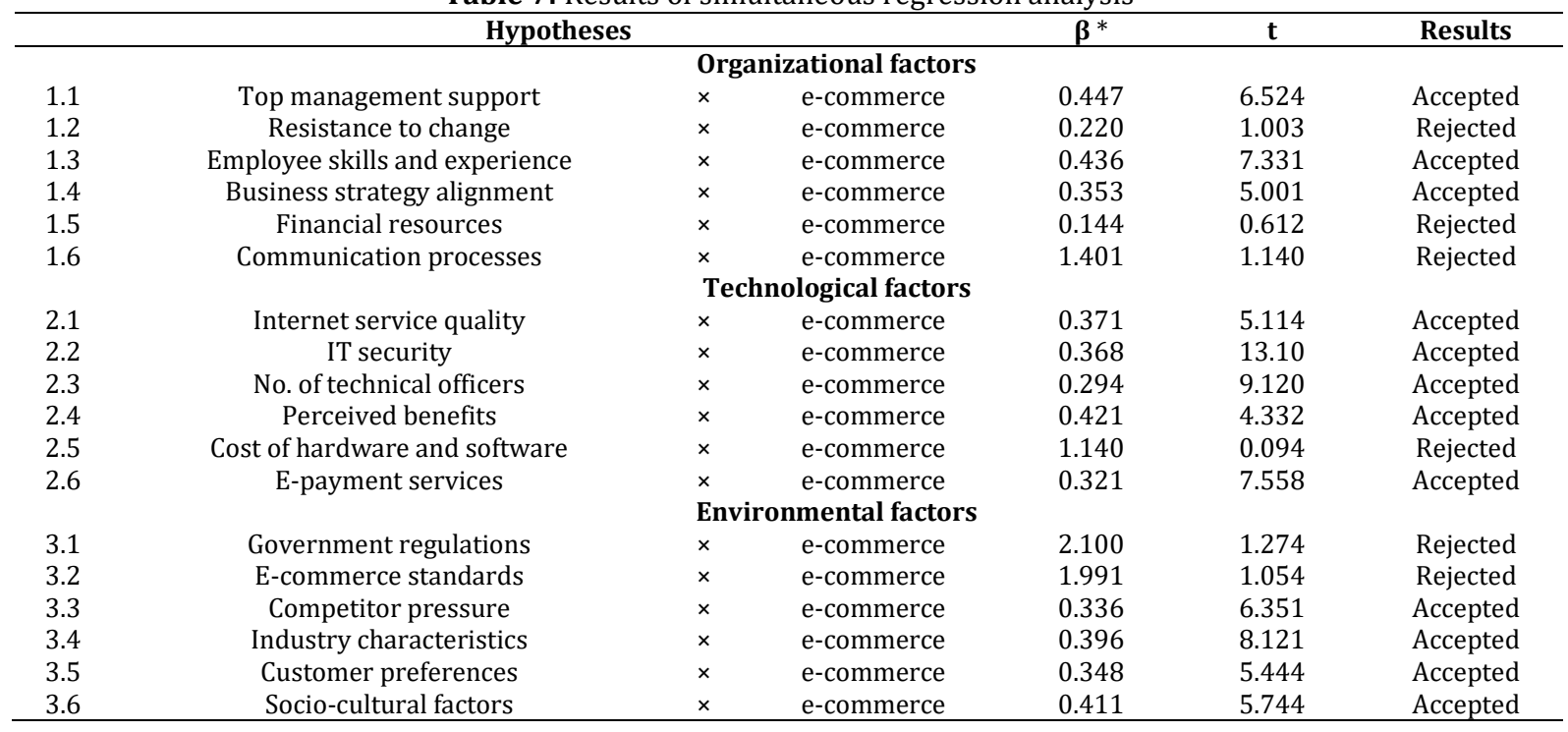

In fact, the absence of these factors was regarded by many authors of previous studies as an inhibitor of e-commerce practice (Shemi and Procter, 2013). Examples of e-commerce barriers found in studies conducted in SMEs include lack of financial resources, security factors, knowledge factors, personal and business social influence, and perceived usefulness of using e-commerce, in addition to a lack of IT skills, customers' preferences for actual shopping rather than online shopping, a lack of top management support, resistance to change, and the high cost of applications (El-Sofany et al., 2012; Bahaddad et al., 2012; Almaimouni et al., 2014; Zafar et al., 2015 and Ezzi, 2015). However, in this study two of the environmental factors (Government regulations and e-commerce standards) show no effect on the practice of ecommerce.

The results of this study indicate that organizational factors, technological factors, and environmental factors, as illustrated by the study, play a significant role in the practice of e-commerce in SMEs, and the results are similar to the study of Zhu and Kraemer (2005).

\section{Conclusion and Further studies}

The aim of this study was to explore the practice of e-commerce among SMEs in Al Qassim region, Saudi Arabia and the obstacles to this practice from the managers' point of view. The results indicated that organizational factors such as top management support, employee skills and experience, and business strategy alignment have significant influences on the practice of e-commerce in SMEs. While the absence of any of the organizational factors (top management support, employee skills and experience, and business strategy alignment) included in this study would create an obstacle to companies' ability in applying e-commerce effectively; no serious hurdle would be experienced if factors such as resistance to change, financial resources, and communication processes were not there.

From the results also it can be concluded that technological factors such as perceived benefits, IT security, e-payment services, and the number of technical officers have a significant effect on the practice of e-commerce by SMEs. This also means that absence of these factors would affect the practice of e-commerce in SMEs. However, no obstacles would exist when the cost of hardware and software rises.

Finally, environmental factors such as sociocultural factors, industry characteristics, customer preferences, and competitor pressure have an influence on the practice of e-commerce. And any shortage of these factors would limit the practice of e-commerce. However, Government regulations and e-commerce standards would not affect the practice of e-commerce in SMEs.

Tsao et al. (2004) have stated that the support of top management is a significant demanding factor for e-commerce practice in businesses. Therefore, the study recommends that policy makers in the company must ensure the support of top management of e-commerce application process, and provide regular training programs to employees to enhance their exposure to e-commerce technology. However, a comprehensive business strategic alignment must be looked at for its importance to improve e-commerce performance as stated by Kartiwi, (2006).

Moreover, the study suggests that benefits of ecommerce should be spread among the employees because of their importance in improving the business process from one side and satisfying customers' needs on the other, Cosgun and 
Dogerlioglu (2012) have confirmed a positive significant relation of perceived benefits on ecommerce conduct. Al-teet and Nakhleh (2014) have suggested in their research that the more secured epayment system is, the more it encourages customers to use the services without inhibition. Nonetheless, e-payment services and IT security remain a crucial issue in businesses; however, companies must provide a secure e-payment system to enhance the effective use of e-commerce. Furthermore, the number of technical officers, according to this research affects the practice of ecommerce and, to prevent it from not becoming an obstacle in the future, the company must employ enough staff to look after the e-commerce practices.

The SMEs practices e-commerce has a great opportunity to create and strengthen their relationships with customers and the market, furthermore protect the image of the company and thus agree with the study of Okadapau and Emaase (2016). Industry characteristics (e.g. Business size, business sector) play a significant role in the practice of e-commerce (Blackburn and Athayde, 2000) Managers need to build and strengthen a long-term relationship with their customers, as well as understand the preferences of the customers. Furthermore, managers must ensure customers' ability to meet their requirements from the ecommerce.

The competitive pressure reflects the degree of pressure felt by the company from its competitors. When competitors adopt e-commerce technology, companies will compete fiercely to adopt ecommerce technology broadly, considering it as a competitive advantage (Zhu and Kraemer, 2005). Thus, companies should always keep an eye on the competitors in their industry, which in return will enable them to adopt e-commerce widely and then create a competitive advantages.

From the research that has been carried out, it is possible to conclude that organizational factors, technological factors, and environmental factors, as illustrated by the study, play a significant role in the practice of e-commerce in SMEs in Al Qassim Region, Saudi Arabia.

\section{Limitation of the study}

More research on the application of e-commerce and its obstacles is still necessary to obtain a definitive answer to the certain variables which affect the use of e-commerce in SMEs. However, there are two main limitations in this research one of which is the sample size; a larger size is preferable to accurately evaluate the practice of e-commerce among SMEs in in Al Qassim region, Saudi Arabia. The types of SMEs selected in this study belonged to different sectors. However it is desirable to focus on particular sector at a time in order to get deeper insight into the preferences for e-commerce applications for different sectors. Thus, the next stage of this research will focus on performing a wider study on the practice of e-commerce and its obstacles.

\section{Acknowledgment}

This study has been conducted by a fund granted from the Deanship of Scientific Research in Qassim University, Saudi Arabia.

\section{References}

Abdulkader S and Abualkishik A (2013). Cloud computing and ecommerce in small and medium enterprises (SME's): The benefits, challenges. International Journal of Science and Research (IJSR), 2(12): 285-288.

Agwu E and Murray P (2015). Empirical study of barriers to electronic commerce adoption by small and medium scale businesses in Nigeria. International Journal of Innovation in the Digital Economy, 6(2): 1-19.

Ajmal F and Yasin NM (2012). Model for electronic commerce adoption for small and medium sized enterprises. International Journal of Innovation, Management and Technology, 3(2): 90-94.

Akanbi T (2016). An investigative study of challenges facing Nigerian small and medium scale enterprises in adoption of ecommerce technology. International Journal of Advances in Management and Economics, 5(1): 22-31.

Al-Alawi A and Al-Ali F (2015). Factors affecting e-commerce adoption in SMEs in the GCC: An empirical study of Kuwait. Research Journal of Information Technology, 7(1): 1-12.

Albugami S and Ahmed V (2015). Success factors for ICT implementation in Saudi secondary schools: From the perspective of ICT directors, head teachers, teachers and students. International Journal of Education and Development Using Information and Communication Technology, 11(1): 3654.

AlGhamdi R, Drew D, and Alkhalaf S (2012). Government initiatives: The missing key for e-commerce growth in KSA. World Academy of Science, Engineering and Technology. Available online at: https://arxiv.org/abs/1211.2398

Almaimouni A, Houghton L, and Sandhu K (2014). Impact of social influence on entrepreneurs to use e-commerce in Saudi Arabia. International Journal of Computer Science and Information Technologies, 5(6): 7761-7772.

Al-teet A and Nakhleh H (2014). The role of e-marketing in the development of internet user attitudes toward tourist sites in Saudi Arabia. Journal of Administrative and Economic Sciences, 7(2):25-44.

Bagale G (2014). Determinants of e-commerce in Indian MSME sector: A conceptual research model based on TOE framework. Universal Journal of Management, 2(3): 105-115.

Bahaddad A, AlGhamdi R, and Houghton L (2012). To what extent would e-mall enable SMEs to adopt e-commerce? International Journal of Business and Management, 7(22): 123-132.

Blackburn R and Athayde R (2000). Making the connection: The effectiveness of internet training in small businesses. Education and Training, 42(4/5): 289-299.

Chen Q and Zhang N (2015). Does e-commerce provide a sustained competitive advantage? An investigation of survival and sustainability in growth-oriented enterprises. Sustainability, (7): 1411-1428.

Chiliya N, Chikandiwa C, and Afolabi B (2011). Factors affecting small micro medium enterprises' (SMMEs) adoption of ecommerce in the Eastern Cape Province of South Africa. International Journal of Business and Management, 6(10): 2836. 
Chivasa S and Hurasha C (2016). Small and medium enterprises (SMEs) adoption and use of e-commerce: A probit modelling. International Journal of Economics, Commerce and Management, 4(3): 218-226.

Cosgun V and Dogerlioglu O (2012). Critical success factors affecting e-commerce activities of small and medium enterprises. Information Technology Journal, 11(12): 16641676

El-Sofany H, Al-Malki T, Al-Zamel A, and Al-Harbi A (2012). Impact of trust factors in improvement and development of ecommerce in Saudi Arabia. International Journal of Computer Applications, 55(9): 15-24.

Ezzi SW (2015). Exploring the characteristics of the e-commerce marketplace in Saudi Arabia. Handbook on Business Strategy and Social Sciences, 3: 1-12.

Fahruzzaman F and Subriadi A (2015). An analysis of e-commerce adoption for small and medium enterprises in Indonesia. In the $1^{\text {st }}$ International Conference on Science and Technology, Postgraduate Program Institut Teknologi Sepuluh Nopember, Surabaya, Indonesia. Available online at: http://iptek.its.ac.id/ index.php/jps/article/view/1046/938

JEG (2016). Small-medium enterprises in Saudi Arabia Report. Jeddah Economic Gateway. Available online at: www.jeg.org.sa

Kartiwi M (2006). Case studies of e-commerce adoption in Indonesia SMEs: The evaluation of strategic use. Australasian Journal of Information Systems, 14(1): 69-80.

Kit S, Osman A, Haji-Othman Y, and Safizal M (2015). E-commerce adoption among small and medium enterprises (SMEs) in Northern State of Malaysia. Mediterranean Journal of Social Sciences, 6(5): 37-43.

Lip-Sam T and Hock-Eam L (2011). Estimating the determinants of B2B e-commerce adoption among small and medium enterprises. International Journal of Business and Society, 12(1): 15-30.

MacGregor R and Vrazalic L (2004). Electronic commerce adoption in small to medium enterprises. A comparative study of SMEs in Wollongong (Australia) and Karlstad (Sweden), University of Wollongong, Wollongong, Australia. Available online at: https://pdfs.semanticscholar.org/1900/3ae1a00e cbbe02d995c6b3ae1012d3fa080f.pdf

Mohammed J, Almsafir M, and Alnaser A (2013). The factors that affects e-commerce adoption in small and medium enterprise: A review. Australian Journal of Basic and Applied Sciences, $7(10)$ : 406-412.

Mutua J, Oteyo I, and Njeru A (2013). The extent of e-commerce adoption among small and medium enterprises in Nairobi, Kenya. International Journal of Business and Social Science, 4(9): 116-122.

Nezakati H, Jofreh M, Liong G, and Asgari O (2012). Assessing ecommerce adoption by small and medium enterprises in Malaysia, Singapore and Thailand. World Applied Sciences Journal, 19(10): 1406-1411

Ochola P (2013). E-commerce adoption among micro, small and medium sector in Nairobi County, Kenya. Ph.D. Dissertation, Kenyatta University, Kenya.

Okadapau MO and Emaase P (2016) Attitude and socio-cultural factors in e-commerce adoption among Smes in Kenya.
International Journal of Engineering and Management Invention, 1(2):62-72

Omri A, Frikha M, and Bouraoui M (2015). An empirical investigation of factors affecting small business success. Journal of Management Development, 34(9): 1073-1093.

Poorangi M, Khin E, Nikoonejad S, and Kardevani A (2013). Ecommerce adoption in Malaysian small and medium enterprises practitioner firms: A revisit on Rogers' model. Annals of the Brazilian Academy of Sciences, 85(4): 15931604.

Rahayu R and Day J (2015). Determinant factors of e-commerce adoption by SMEs in developing country: Evidence from Indonesia. Procedia Social and Behavioral Sciences, 195: 142 150.

Rehman SU and Alam R (2016). A study of barriers to e-commerce adoption among SMEs in Malaysia. University of Modern Sciences, 1(1): 45-58.

Rumanyika J and Mashenene R (2014). Impediments of ecommerce adoption among small and medium enterprises (SMEs) in Tanzania: A review. International Journal of Information Technology and Business Management, 32(1): 45-55.

Senarathna R and Wickramasuriya $H$ (2001). Organizational factors affecting e-commerce adoption in small and mediumsized enterprises. Tropical Agricultural Research, 22(2): 204210.

Shemi A (2012). Factors affecting e-commerce adoption in small and medium enterprises (SMEs): An interpretive study of Botswana. Ph.D. Dissertation, University of Salford, Manchester, England.

Shemi A and Procter CT (2013). Challenges of e-commerce adoption in SMEs: An interpretive case study of Botswana. Botswana Journal of Business, 6(1): 17-30.

Tsao H, Lin KH, and Lin C (2004). An investigation of critical success factors in the adoption of B2BEC by Taiwanese companies. Journal of American Academy of Business, 5(1): 198-202.

Wilson H, Daniel E, and Davies I (2008). The diffusion of ecommerce in UK SMEs. Journal of Marketing Management, 24(5-6): 489-516.

Zafar A, Almaleh A, Alshahri S, Alqahtani S, and Alqahtani N (2015). Role of information systems in KSA small and medium enterprises (SMEs). International Journal of Advanced Research in Computer and Communication Engineering, 4(5): 6-11.

Zaied A (2012). Barriers to e-commerce adoption in Egyptian SMEs. International Journal of Information Engineering and Electronic Business, 4(3): 9-18.

Zhu K and Kraemer KL (2002). E-commerce metrics for Netenhanced organizations: Assessing the value of e-commerce to firm performance in the manufacturing sector. Information Systems Research, 13(3): 275-295

Zhu K and Kraemer KL (2005). Post-adoption variations in usage and value of e-business by organizations: Cross-country evidence from the retail industry. Information Systems Research, 16(1): 61-84. 